ARTICLE

https://doi.org/10.1038/s41467-019-12938-4

\title{
Tuning wettability of molten lithium via a chemical strategy for lithium metal anodes
}

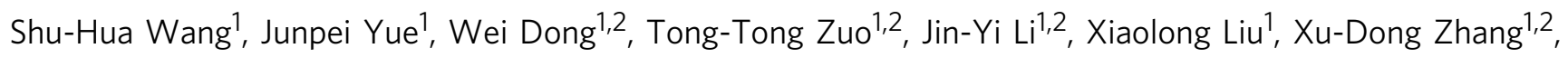
Lin Liu¹,2, Ji-Lei Shi (1) ${ }^{1,2}$, Ya-Xia Yin ${ }^{1,2} \&$ Yu-Guo Guo (1) ${ }^{1,2 \star}$

Metallic lithium affords the highest theoretical capacity and lowest electrochemical potential and is viewed as a leading contender as an anode for high-energy-density rechargeable batteries. However, the poor wettability of molten lithium does not allow it to spread across the surface of lithiophobic substrates, hindering the production and application of this anode. Here we report a general chemical strategy to overcome this dilemma by reacting molten lithium with functional organic coatings or elemental additives. The Gibbs formation energy and newly formed chemical bonds are found to be the governing factor for the wetting behavior. As a result of the improved wettability, a series of ultrathin lithium of 10-20 $\mu \mathrm{m}$ thick is obtained together with impressive electrochemical performance in lithium metal batteries. These findings provide an overall guide for tuning the wettability of molten lithium and offer an affordable strategy for the large-scale production of ultrathin lithium, and could be further extended to other alkali metals, such as sodium and potassium.

\footnotetext{
${ }^{1}$ CAS Key Laboratory of Molecular Nanostructure and Nanotechnology, CAS Research/Education Center for Excellence in Molecular Sciences, Beijing National Laboratory for Molecular Sciences (BNLMS), Institute of Chemistry, Chinese Academy of Sciences (CAS), 100190 Beijing, China. ${ }^{2}$ University of Chinese Academy of Sciences, 100049 Beijing, China. *email: ygguo@iccas.ac.cn
} 
T he rapid development of renewable clean energy technologies and the affiliated energy storage demand drive the intensive on-going research on high-energy-density (HED) rechargeable batteries ${ }^{1-8}$. Lithium $(\mathrm{Li})$ metal rechargeable batteries are promising HED devices because Li metal anodes offer high specific capacity $\left(3860 \mathrm{~mA} \mathrm{~h}^{-1}\right)$ and low electrochemical potential $(-3.04 \mathrm{~V} \text { vs. standard hydrogen electrode })^{7,9-17}$. Ultrathin Li with proper capacity (e.g., $3-6 \mathrm{~mA} \mathrm{~h} \mathrm{~cm}^{-2}, 15-30$ $\mu \mathrm{m})$ rather than commercial Li foils $\left(\sim 110 \mathrm{~mA} \mathrm{~h} \mathrm{~cm}^{-2}, 550 \mu \mathrm{m}\right)$ is important for matching with state-of-art cathodes ${ }^{3,15-19}$, which are highly desired in HED Li batteries and prelithiation technology for silicon anodes ${ }^{20-22}$. It is a challenge to prepare the ultrathin Li with a thickness of $15-30 \mu \mathrm{m}$ by rolling commercially thick Li foil, considering the poor mechanical properties and sticky issues of metallic Li during the rolling process. Spreading molten $\mathrm{Li}$ on $\mathrm{Cu}$ current collectors might be a promising strategy to realize the large-scale and low-cost preparation of ultrathin $\mathrm{Li}^{23-26}$. Unfortunately, this method suffers from the poor wettability of molten Li on various substrates. As a result, tuning the wettability of molten $\mathrm{Li}$ is of great importance in the field of $\mathrm{Li}$ metal batteries $27-33$.

Fundamentally, the spreading of molten Li requires high lithiophilicity of the substrate $23,24,26,28,29,31,33$. Most metal current collectors (e.g., $\mathrm{Cu}$ and $\mathrm{Ni}$ foam) and carbon materials used in Li metal batteries are lithiophobic to molten $\mathrm{Li}$; furthermore, molten $\mathrm{Li}$ presents a liquid sphere on these substrates $24,26,33$. Accordingly, these substrates cannot be directly used as current collectors to spread molten Li. Recently, applying a thin interlayer, such as $\mathrm{Al}_{2} \mathrm{O}_{3}, \mathrm{Si}, \mathrm{Mg}, \mathrm{Ge}, \mathrm{Sn}$, and $\mathrm{ZnO}$, has been proven effective inconsiderably improving molten $\mathrm{Li}$ wettability $23-25,28,33$. Nano-scalethick interlayers have been realized via atomic layer deposition or chemical vapor deposition ${ }^{33}$. However, these surface modification technologies under high vacuum are time-consuming and costly ${ }^{24}$. Thus, highly effective and practical methods for tuning the wettability of molten Li must be explored.

Here we report the improvement of wettability of molten $\mathrm{Li}$ through systematic interphase design. The method is applicable to various substrates, and several types of ultrathin $\mathrm{Li}$ anode with thickness of 10-40 $\mu \mathrm{m}$ can be successfully achieved. First, a series of organic functional coatings can perfectly solve the poor wettability of molten Li. Many elemental additives that can react with molten $\mathrm{Li}$ can tune the surface energy of molten $\mathrm{Li}$ and hence facilitate the homogenous spreading of metallic $\mathrm{Li}$ on various substrates. Key parameters, such as $\Delta r G$ and newly formed chemical bonds, are found to be the governing factor for the improved wettability. The successful application of ultrathin $\mathrm{Li}$ anodes in rechargeable batteries highlights the importance of our strategy to improve the wettability of molten $\mathrm{Li}$ and further develop $\mathrm{Li}$ metal batteries toward next-generation energy storage systems.

\section{Results}

Preparation of ultrathin Li by tuning wettability of molten Li. Constructing the appropriate interphase that facilitates the spread of molten Li onto the substrate is fundamental for ultrathin $\mathrm{Li}$ preparation (Fig. 1a-d). Herein, we developed a facile and lowcost chemical strategy for producing ultrathin Li anodes by introducing organic compounds with a functional group, such as $-\mathrm{COOH},-\mathrm{OH},-\mathrm{SO}_{3} \mathrm{H},-\mathrm{NH}_{2},-\mathrm{NH},-\mathrm{PO}_{4},-\mathrm{Si}-\mathrm{O},-\mathrm{F},-\mathrm{Cl},-\mathrm{Br}$, or -I, coated onto the substrates via a doctor-blade coating method (Fig. 1e). The reactions of the molten Li with organic compounds are the main driving force for the improved wettability. Therefore, designing the interphase reactions is the key step for the improved wettability.

The poor lithiophilicity of molten $\mathrm{Li}$ results in spherical $\mathrm{Li}$ beads rather than thin layers formed onto diverse substrates, including planar copper, foamed iron, foamed nickel, carbon fiber, and oxidized graphite, within the temperature range of $180-300^{\circ} \mathrm{C}$ (Fig. 2a-f, Supplementary Movie 1). The contact angles of molten $\mathrm{Li}$ on these substrates were relatively large, (e.g., $\sim 140^{\circ} \mathrm{C}$ at a temperature of $250^{\circ} \mathrm{C}$ for planar Cu; Fig. $2 \mathrm{~g}$ ). Abietic resin, a renewable and abundant acid in nature, is normally used as solder. Herein, it was used for the first time as a functional coating to modify the lithiophobic substrates. When abietic resin contacted with molten $\mathrm{Li}$, a thermal decomposition reaction of abietic resin occurred (Supplementary Movie 2), and the resultant decomposition products immediately reacted with molten Li to form a new interphase. This reaction dramatically improved the wettability of molten $\mathrm{Li}$ and consequently formed ultrathin $\mathrm{Li}$ onto those lithiophobic substrates (Fig. $2 \mathrm{~h}-\mathrm{l}$ and Supplementary Movie 2-4). This process required $<5$ s for molten $\mathrm{Li}$ to spread across the substrates. Hence, it is easy to scale up for the continuous production of ultrathin Li. The result illustrates that the surface modification of $\mathrm{Cu}$ foil by abietic resin allows for good lithiophilicity with molten $\mathrm{Li}$ to generate ultrathin $\mathrm{Li}$.

The formed ultrathin $\mathrm{Li}$ with thickness of $\sim 12 \mu \mathrm{m}$ (Fig. $2 \mathrm{~m}, \mathrm{n}$ ) was characterized by X-ray diffraction (XRD), and all characteristic diffraction peaks could be identified as Li (Fig. $2 \mathrm{~m}$ ). The elemental analysis of electron microprobe analysis (EPMA) indicated that carbon was concentrated at the bottom surface of the Li layer (Fig. 2o). This carbon-enriched layer may mainly originate from the thermal decomposition of abietic resin. Interestingly, in addition to planar $\mathrm{Cu}$ substrate, ultrathin $\mathrm{Li}$ layers were also successfully prepared via abietic resin coatings on various substrates with different porous structures (e.g., $\mathrm{Cu}$, carbon, and $\mathrm{TiO}_{2}$ ) with pore sizes ranging from nano to macro (Supplementary Figs. 1 and 2a). This result suggests that the coatings on substrates are the key point to govern the wettability of molten Li rather than pore structures or substrate constituents. Notably, when the concentration of abietic resin solution was further increased from 10 to $40 \mathrm{wt} \%$, the molten $\mathrm{Li}$ could successfully infuse into the pores of carbon fiber felt (Supplementary Fig. 2b). This result indicates that the composite Li metal anode with three-dimensional (3D) conducting scaffold could be prepared easily by controlling the thickness of abietic resin.

Furthermore, we attempted a series of organic coatings containing functional groups of $-\mathrm{COOH}$ to determine the key factors for the improved wettability (Supplementary Table 1). Suitable melting points $\left(24-275^{\circ} \mathrm{C}\right)$ and boiling points $\left(>150^{\circ} \mathrm{C}\right)$ are the critical factors for the improved wettability. When the number of functional groups of $-\mathrm{COOH}$ was increased, dicarboxylic acids, such as oxalic acid, exhibited better performance for improving wettability than monocarboxylic acids, such as acetic acid or aminoacetic acid. It should be emphasized that the wettability of the organic coating on $\mathrm{Cu}$ substrate is commonly ignored, which is mainly determined by its physical properties and the selected solvents. Fortunately, the selected organic coating in a proper solvent could have good wettability on $\mathrm{Cu}$ substrates and thus facilitate molten Li spreading along substrates.

Mechanism of improved wettability via abietic resin. As previously mentioned, diverse organic coatings have been used to improve the wettability of molten $\mathrm{Li}$, and some empirical selection rules have been summarized. We sought to determine the dominating factors governing the improved wettability of molten Li. Thus, we conducted systematic studies to uncover the underlying mechanism.

The morphology and element distribution of the top surface of ultrathin Li prepared from abietic resin were characterized by EPMA (Supplementary Fig. 3). The smooth top surface had similar compositions with commercial $\mathrm{Li}$ foil with carbon and oxygen 

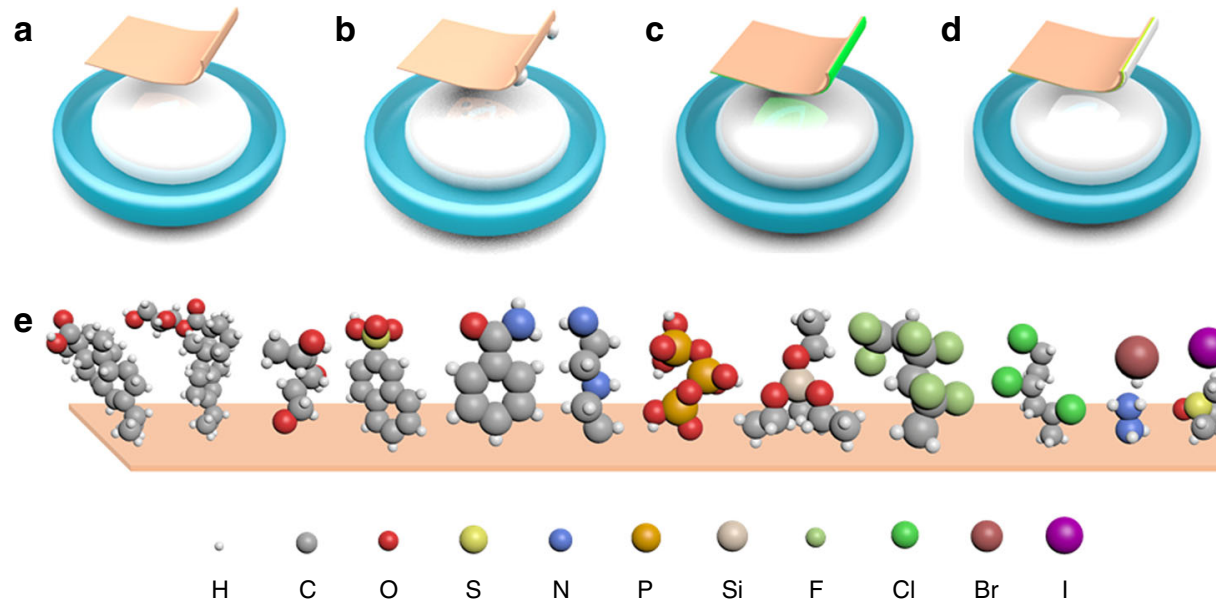

Fig. 1 Schematic of an ultrathin Li layer formed onto lithiophobic substrates. Contact schematic of molten Li and the Cu substrate without (a, b) and with (c, d) the functional coating. e Molecular structures of various functional coatings
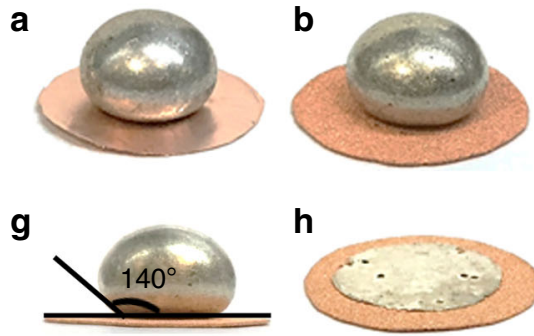

h
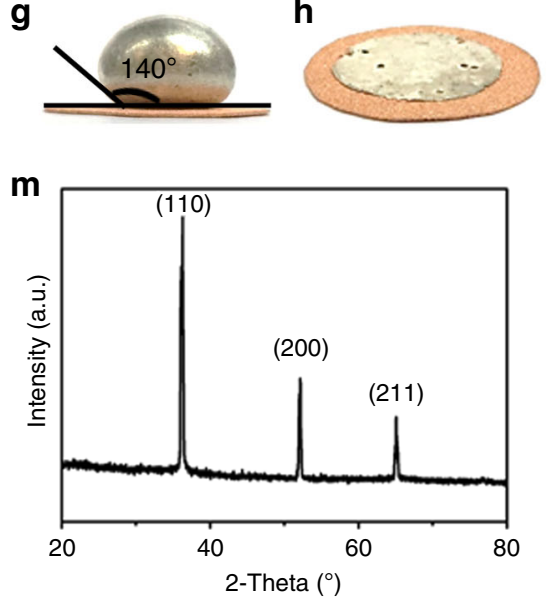
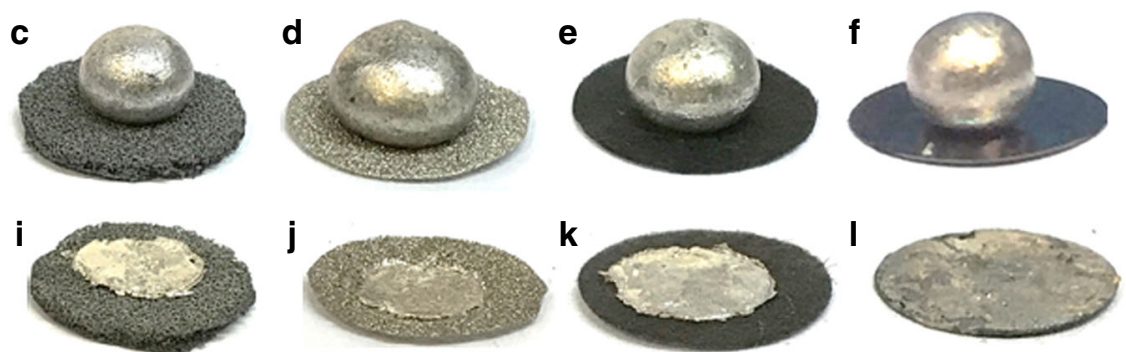

n

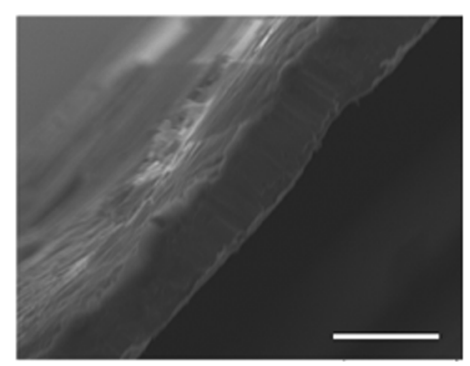

$\mathbf{0}$

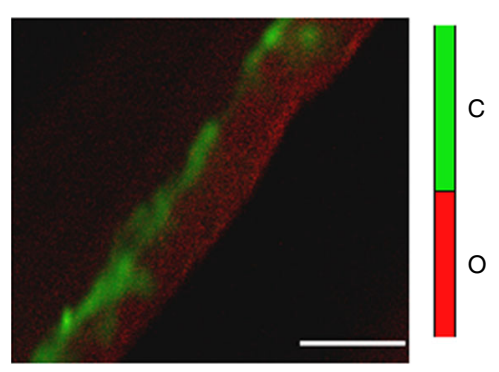

Fig. 2 Wettability of molten Li onto various substrates and the prepared ultrathin Li layer. Molten Li shows a poor wettability on planar Cu (a), copper foam (b), iron foam (c), nickel foam (d), carbon fiber (e), and oxidized graphite (f). $\mathbf{g}$ The contact angle of planar Cu is $140^{\circ}$. With the organic coating of abietic resin, the surface wetting of molten Li onto various substrates is improved. Ultrathin Li is formed on copper foam (h), iron foam (i), nickel foam ( $\mathbf{j}$ ), carbon fiber (k), and oxidized graphite (I). $\mathbf{m}$ XRD of prepared ultrathin Li. $\mathbf{n}$ EPMA image of ultrathin Li. o Elemental distribution image of $\mathbf{C}$ and $\mathrm{O}$ on the ultrathin Li. Scale bars are $20 \mu \mathrm{m}$ in $\mathbf{n}, \mathbf{o}$

contents of 7.32 and $92.68 \mathrm{wt} \%$, respectively. This result indicates that the possible components of $\mathrm{Li}, \mathrm{Li}_{2} \mathrm{O}, \mathrm{LiOH}$, and $\mathrm{Li}_{2} \mathrm{CO}_{3}$ existed at the top surface of ultrathin $\mathrm{Li}$, and were derived from the inevitable slight oxidation of Li even in an argon-filled glove box. The Li layer was then peeled off from $\mathrm{Cu}$ substrate to expose the bottom surface of the ultrathin Li (Fig. 3a). EPMA results indicate that the interphase was composed of $\mathrm{C}(52.19 \mathrm{wt} \%)$ and $\mathrm{O}$ $(47.81 \mathrm{wt} \%)$, as shown in Fig. 3b. Fourier transform infrared spectroscopy (FTIR; Fig. 3c, in combination with Supplementary Fig. $4 \mathrm{a}, \mathrm{b})$ confirms the existence of methyl and methylene groups $\left(2900 \mathrm{~cm}^{-1}\right)$, as well as $\mathrm{LiOH}$ at the bottom surface of Li layer. Xray photoelectron spectroscopy (XPS) was used to identify the chemical state of the interphase. The $\mathrm{C} 1 \mathrm{~s}$ spectrum could be deconvoluted into three peaks with binding energies of 284.8, 286.5 , and $289 \mathrm{eV}$, which can be assigned to $\mathrm{C}-\mathrm{H}$ and/or $\mathrm{C}-\mathrm{C}$, $\mathrm{C}-\mathrm{O}$, and -COO-. The peak intensity for $\mathrm{C}-\mathrm{O}$ and $-\mathrm{COO}-$ was smaller compared with that in abietic resin (Fig. 3g), implying the decomposition of abietic resin. Two deconvoluted peaks in $\mathrm{Li} 1 \mathrm{~s}$ spectrum could be assigned to $\mathrm{LiOH}(54.9 \mathrm{eV})$ and $\mathrm{Li}_{2} \mathrm{O} /-\mathrm{COOLi}$ $(55.6 \mathrm{eV})$. In combination with the above analysis, the compositions of carbon-enriched interphase can be deduced as follows: carbonaceous products, $\mathrm{LiOH}$, and $-\mathrm{COOLi} / \mathrm{Li}_{2} \mathrm{O}$. Moreover, the chemical compositions of the interphase were similar over the temperature range of $180-300^{\circ} \mathrm{C}$ (Fig. 3c), which allowed for a broad temperature range for abietic resin to improve wettability.

We then performed time-of-flight secondary ion mass spectrometry (Tof-SIMS) and XPS depth-profile study to determine the element distributions of the interphase from the bottom surface to bulk. The Tof-SIMS results in Fig. $3 \mathrm{~d}-\mathrm{f}$ show that $\mathrm{Li}^{+}$content increased with the etching depth, whereas $\mathrm{C}^{+}$content decreased. This finding implies that carbonaceous products gradually decreased with depth. The XPS depth profiles in Supplementary 

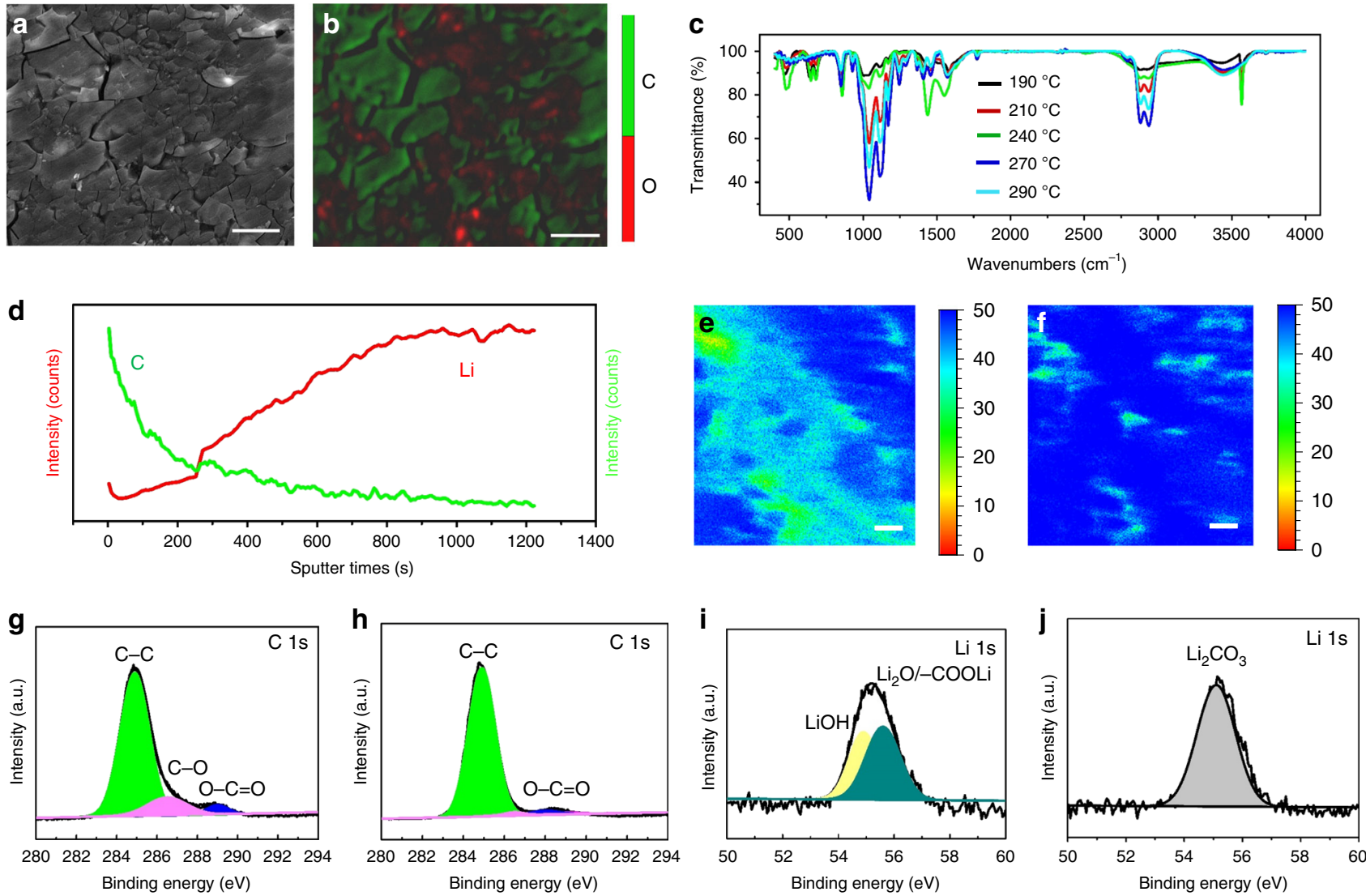

Fig. 3 Mechanism of improved wettability on planar Cu by coating the substrate with abietic resin. a EPMA image of the bottom surface of ultrathin Li when it peeled off from the Cu substrate. $\mathbf{b}$ Elemental distribution image of $\mathrm{O}$ and $\mathrm{C}$ on the bottom surface. $\mathbf{c}$ Fourier infrared spectra of ultrathin Li on the bottom surface of the substrate. $\mathbf{d}$ Elemental distribution of $\mathrm{Li}^{+}$and $\mathrm{C}^{+}$probed via Tof-SIMS. e Elemental distribution map of $\mathrm{Li}^{+}$on the bottom surface of ultrathin $\mathrm{Li}$ after etching 50 layers. $\mathbf{f}$ Elemental distribution map of $\mathrm{Li}^{+}$on the bottom layer of ultrathin Li after etching 179 layers. $\mathbf{g}$ XPS spectra of $\mathrm{C}$ 1s for the abietic resin coating. XPS spectra of C 1s (h) and Li 1s (i) on the bottom surface of ultrathin Li layer when peeled off from the Cu substrate. $\mathbf{j}$ XPS spectra of Li 1s for the bottom surface of ultrathin Li after the carbon-enriched layer was removed by DOL. Scale bars are $20 \mu \mathrm{m}$ in $\mathbf{a}, \mathbf{b}, \mathbf{e ,} \mathbf{f}$

Figs. 5a, b further confirm these results. The compositions in the bulk were quite different from those on the bottom surface, where the peaks of Li $1 s$ shifted to high binding energy (Supplementary Fig. 5b). Notably, the characteristic peaks of $\mathrm{LiC}_{6}$ and $\mathrm{Li}_{2} \mathrm{C}_{2}$ at 57.1 and $56.2 \mathrm{eV}$ have been obtained through XPS simulation ${ }^{34,35}$, and $\mathrm{Li}_{2} \mathrm{C}_{2}$ and $\mathrm{LiC}_{6}$ can form according to the $\mathrm{Li}-\mathrm{C}$ phase equilibria ${ }^{36}$. The $\mathrm{Li}_{2} \mathrm{O} /-\mathrm{COOLi}$, $\mathrm{LiOH}$ (Fig. $3 \mathrm{i}$ ), $\mathrm{LiC}_{6}$, and $\mathrm{Li}_{2} \mathrm{C}_{2}$ (Supplementary Fig. $5 \mathrm{~b}-\mathrm{d}$ ) on the interphase possibly originated from the reaction of molten $\mathrm{Li}$ with the decomposition products of abietic resin (trace water and pyrolyzed carbon). With increased etched depth, the contents of $\mathrm{LiOH}$ and $\mathrm{Li}_{2} \mathrm{O} /-\mathrm{COOLi}$ significantly decreased, and those of $\mathrm{LiC}_{6}$ and $\mathrm{Li}_{2} \mathrm{C}_{2}$ increased. The different distributions of $\mathrm{LiOH}, \mathrm{Li}_{2} \mathrm{O} /-\mathrm{COOLi}, \mathrm{LiC}_{6}$, and $\mathrm{Li}_{2} \mathrm{C}_{2}$ across the interphase reveal that the formed $\mathrm{LiC}_{6}$ and $\mathrm{Li}_{2} \mathrm{C}_{2}$ could suppress the diffusion of water vapor to the ultrathin $\mathrm{Li}$. This result provides a new idea for the protection of Li against oxidation. In other words, these results indicate that the new interphase from abietic resin consisted of a mixture of $\mathrm{LiOH}, \mathrm{Li}_{2} \mathrm{O} /-\mathrm{COOLi}, \mathrm{LiC}_{6}, \mathrm{Li}_{2} \mathrm{C}_{2}$, carboxy, methyl group, and methylene groups. The formation of the $\mathrm{Li}-\mathrm{O}$ and $\mathrm{Li}-\mathrm{C}$ bonds is the main driving force for the improved wettability of molten Li. For other carboxylic acids, such as citric acid, the mechanism for improved wettability is similar to that of abietic resin (Supplementary Fig. 6) because of the similar chemical properties from the carboxyl group.

It should be emphasized that the carbon-enriched interphase could be removed through washing with 1,3-dioxolane (DOL), offering a feasible procedure to eliminate the as-formed carbonenriched interphase. The peak of $\mathrm{Li}_{2} \mathrm{CO}_{3}$ on $\mathrm{Li}$ metal at $55.1 \mathrm{eV}$ was clearly detected at the bottom surface of ultrathin Li (Fig. 3j) after washing DOL. This peak might have originated from the oxidization of ultrathin Li during the washing process. Notably, the Li $1 s$ binding energy of pure Li metal was $53.7 \mathrm{eV}$, but was difficult to be detected because of the inevitable oxidation of Li.

Improved wettability via other organic coatings. Inspired by the chemical reaction between $\mathrm{Li}$ and abietic acid, we explored additional organic coatings from compounds containing $-\mathrm{OH}$, $-\mathrm{SO}_{3} \mathrm{H},-\mathrm{NH}_{2},-\mathrm{NH},-\mathrm{PO}_{4},-\mathrm{Si}-\mathrm{O},-\mathrm{F},-\mathrm{Cl},-\mathrm{Br}$, or $-\mathrm{I}$ to improve the wettability of molten Li. Organic 2-naphthalenesulfonic acid with functional group of $-\mathrm{SO}_{3} \mathrm{H}$ was investigated for improved wettability. The appearance of $\mathrm{LiOH}$ peak reveals that $\mathrm{H}$ in $-\mathrm{SO}_{3} \mathrm{H}$ might play the same role with the $\mathrm{H}$ in $-\mathrm{COOH}$ (Supplementary Fig. 7). The peak at $54.5 \mathrm{eV}$ could be attributed to $\mathrm{LiOH}$ or $\mathrm{Li}-\mathrm{O}$. Thus, the $\mathrm{H}$ in $-\mathrm{SO}_{3} \mathrm{H}$ might have been replaced by $\mathrm{Li}$ during the contact of $\mathrm{Li}$ with 2 -naphthalenesulfonic acid, which was based on the displacement reaction between acids and metals. As the displacement reaction could be considered for improving the wettability of molten $\mathrm{Li}$, tetraethyl orthosilicate (TEOS) was also coated onto planar $\mathrm{Cu}$. TEOS could improve the wettability of molten $\mathrm{Li}$. XPS peaks of $\mathrm{SiO}_{2}$ and $\mathrm{SiO}_{x}-\mathrm{Li}$ at 102.99 $\mathrm{eV}$ and $102.2 \mathrm{eV}$ suggest the thermal decomposition of TEOS after the reaction (Supplementary Fig. $8 \mathrm{a}-\mathrm{c}$ ). The appearance of $\mathrm{SiO}_{x}-\mathrm{Li}$ might be due to the new phase $\mathrm{SiO}_{x}$ reacting with molten $\mathrm{Li}$ or molten $\mathrm{Li}$ directly displacing the ethyl group in TEOS. When the bottom surface of ultrathin $\mathrm{Li}$ was peeled off from the 
$\mathrm{Cu}$ substrate and washed by DOL, the characteristic peaks of the $\mathrm{Li}_{2} \mathrm{CO}_{3}(55.1 \mathrm{eV})$ and $\mathrm{Li}_{2} \mathrm{O}(55.6 \mathrm{eV})$ were observed as expected (Supplementary Fig. 8d).

Aside from the $\mathrm{Li}-\mathrm{O}$ bond, $\mathrm{Li}-\mathrm{N}$ bond could also be designed to improve wettability. The reaction mechanisms of molten $\mathrm{Li}$ with benzamide were confirmed with XPS analysis (Supplementary Fig. 9). After the contact of molten Li with benzamide, a peak from $-\mathrm{N}-\mathrm{Li}$ was observed, suggesting that a displacement reaction occurred between Li and benzamide. Similarly, polyethyleneimine (PEI) was also used to improve wettability. The structure of PEI was not changed after the heat treatment (Supplementary Fig. 10), suggesting that no thermal decomposition occurred at $300^{\circ} \mathrm{C}$. Thus, the detected N-Li (398 eV) in Supplementary Fig. 11b confirms that the $\mathrm{H}$ in $-\mathrm{N}-\mathrm{H}$ was directly displaced by $\mathrm{Li}$.

Apart from the new bonds of $\mathrm{Li}-\mathrm{O}$ or $\mathrm{Li}-\mathrm{N}$, other newly formed bonds, such as $\mathrm{Li}-\mathrm{F}, \mathrm{Li}-\mathrm{Cl}, \mathrm{Li}-\mathrm{Br}$, and $\mathrm{Li}-\mathrm{I}$, could also be designed. As expected, polyvinylidene fluoride (PVDF) coating successfully improved the wettability of molten $\mathrm{Li}$, causing the ultrathin $\mathrm{Li}$ to spread onto the substrate. $\mathrm{LiF}$ could be detected from the Raman spectra when the ultrathin Li was peeled off from the substrate, which agrees with the commercial LiF powder (Supplementary Fig. 12a, b). Li-F (55.7 eV) and C-Li $(55.2 \mathrm{eV})$ were also detected from XPS analysis (Supplementary Fig. 13), which indicates that the reaction of molten Li with PVDF is a complex chemical reaction. The change in FTIR spectra shows the changed structure from $\beta$-phase PVDF to $\alpha$-phase PVDF at $300{ }^{\circ} \mathrm{C}$ (Supplementary Fig. 14). As a result, the observed C-Li at $55.2 \mathrm{eV}$ originated from the displacement reaction between the molten $\mathrm{Li}$ and $\alpha$-phase PVDF. However, it is a challenge to determine the specific substitution position of $\mathrm{Li}$ in PVDF. Beyond the new bonds of $\mathrm{Li}-\mathrm{F}$ and $\mathrm{Li}-\mathrm{C}$, organic coatings in Supplementary Table 2 containing groups of $-\mathrm{Br},-\mathrm{Cl}$, and $-\mathrm{I}$ were also designed to form new bonds containing $\mathrm{Li}-\mathrm{Br}, \mathrm{Li}-\mathrm{Cl}$, and $\mathrm{Li}-\mathrm{I}$, respectively. Hydrazine monohydrobromide, polyvinylchloride, and trimethylsulfoxonium iodide were coated onto the planar $\mathrm{Cu}$ substrate to improve the wettability of molten Li. The physical properties of these coatings are summarized in Supplementary Table 2. All of these formed new bonds contributed to improved wettability (Supplementary Table 3). The explored organic coatings exhibit great potential for tuning the wettability of molten $\mathrm{Li}$ because the coating process on substrates is quite simple and can be easily applied to a large-scale preparation. The prepared ultrathin $\mathrm{Li}$ with an area size of 6.5 $\mathrm{cm} \times 4 \mathrm{~cm}$ is shown in Supplementary Fig. 15 .

Improved wettability based on elemental additives to molten Li. The surface tension of molten Li could be decreased to improve the wettability of molten $\mathrm{Li}$ on lithiophobic substrates. A directalloying method that involves adding carbon materials or tin into molten $\mathrm{Li}$ could improve the wettability of molten $\mathrm{Li}^{24,37}$. Other elements, such as indium (In) and magnesium $(\mathrm{Mg})$ could also be successfully used to decrease the surface tension of molten $\mathrm{Li}$ at temperature ranges of $200-300^{\circ} \mathrm{C}$. Metal liquids with a decreased surface tension could spread onto $\mathrm{Cu}$ substrates (Supplementary Fig. 16). Thus, ultrathin $\mathrm{Li}$ alloy layers were successfully generated.

Typically, the surface tension of molten Li significantly decreased upon adding $10 \mathrm{wt} \%$ In into molten $\mathrm{Li}$, and the molten $\mathrm{Li}$-In could spread on the stainless steel with negligible contact angles after more than $10 \mathrm{~min}$. When the amount of In was increased to $50 \mathrm{wt} \%$, surface tension decreased, and molten $\mathrm{Li}$ spread on $\mathrm{Cu}$ substrates easily, suggesting that more In content is beneficial to weakening the inter-atomic force of $\mathrm{Li}$. The as-prepared ultrathin $\mathrm{Li}_{x} \mathrm{In}_{y}$ anodes on planar $\mathrm{Cu}$ were characterized via EPMA (Supplementary Fig. 17a \pm d), identifying the existence of In in the prepared anodes. Only one XRD peak $\left(36.26^{\circ}\right)$ of $\operatorname{Li}_{x} \operatorname{In}_{y}$ was observed on planar $\mathrm{Cu}$ substrates
(Supplementary Fig. 17e), because other peaks for $\mathrm{Li}_{x} \operatorname{In}_{y}$ were too weak to observe under extremely strong ground peaks from $\mathrm{Cu}$ substrate. When In content was increased to $\sim 94 \mathrm{wt} \%$, the LiIn alloy with the strongest peak of $37.28^{\circ}$ was observed from XRD (Supplementary Fig. 17f). All of these results confirm the new bond formation, which decreased surface tension of molten $\mathrm{Li}$, and improved wettability onto $\mathrm{Cu}$ substrates. Furthermore, other elemental additives [such as S (10 wt\%), Se (50 wt \%), Te (40 wt\%), Bi (50 wt \%), Pb (50 wt\%), Ga (40 wt\%), Cd (50 wt\%), Hg (50 wt\%), Pd (50 wt\%), Sc (20 wt\%), Y (40 wt\%), Mg (28 wt\%), Ca (40 wt\%), Sr (50 wt $\%)$, and $\mathrm{Ba}(50 \mathrm{wt} \%)]$ were explored to decrease surface tension (Supplementary Table 4). After these alloying elemental additives were introduced into the molten $\mathrm{Li}$, the surface tension of molten $\mathrm{Li}$ decreased, and the liquid metals could directly spread onto the planar $\mathrm{Cu}$ substrates, which agrees with a previous report of $\mathrm{Sn}^{24}$. These results suggest that adding alloying elements into molten $\mathrm{Li}$ is a general strategy to decrease the surface energy of the molten $\mathrm{Li}$ and improve wettability. As a result, the ultrathin Li composite could be prepared on lithiophobic substrates by decreasing the surface tension of liquid metals.

$\mathrm{Li}$ anodes with different thickness on $\mathrm{Cu}$ substrate were prepared via the PVDF coatings or via the elemental additives into the molten Li (Supplementary Fig. 18a-d). In comparison with the ultrathin $\mathrm{Li}$ prepared via organic coatings, ultrathin $\mathrm{Li}$ prepared by adding elemental additives could not be easily peeled off from the Cu substrate (Supplementary Fig. 18c, d). Ultrathin $\mathrm{Li}$ with thickness of $\sim 40 \mu \mathrm{m}$ was obtained (Supplementary Fig. 18d). The thickness of ultrathin $\mathrm{Li}$ on planar $\mathrm{Cu}$ could be regulated from several aspects, including temperature, composition of molten $\mathrm{Li}$, and lithiophilic Pt coating on the planar $\mathrm{Cu}$. The thickness of $\mathrm{Li}$ on the $\mathrm{Cu}$ substrate decreased with the increase in temperature from 250 to $500{ }^{\circ} \mathrm{C}$ (Supplementary Fig. 18e). In addition to the temperature of metal liquids, the composition of the metal liquids is a critical factor that determines the thickness of Li. In particles were added into the molten $\mathrm{Li}$ to form metal liquids at $300^{\circ} \mathrm{C}$. The thickness of $\mathrm{Li}$ on the $\mathrm{Cu}$ substrate increased with the In content. Furthermore, the thickness could also be tuned by coating lithiophilic Pt on the planar $\mathrm{Cu}$. The different Li thickness might be attributed to the difference in the surface tension of the molten metal.

Electrochemical testing of ultrathin Li. To evaluate the practicability of the resulting ultrathin $\mathrm{Li}$, we utilized it as anodes in $\mathrm{Li}$ metal batteries. The areal capacity from 3.5 to $9 \mathrm{~mA} \mathrm{~h} \mathrm{~cm}^{-2}$ could be easily obtained by tuning the thickness of ultrathin Li (Supplementary Fig. 19a-c). The prepared ultrathin Li anode via PVDF exhibited a stable voltage profile with a small hysteresis $(\sim 40 \mathrm{mV})$, even after cycling for $500 \mathrm{~h}$ at the current density of 1 $\mathrm{mA} \mathrm{cm}{ }^{-2}$ with capacity of $2 \mathrm{mAh} \mathrm{cm}^{-2}$ (Supplementary Fig. 19d). The ultrathin Li prepared via PVDF coating on planar $\mathrm{Cu}$ current collectors was used as $\mathrm{Li}$ anodes, and commercial $\mathrm{LiFePO}_{4}$ was used as cathode (Supplementary Fig. 19e). The thickness of $\mathrm{Li}$ (e.g., the Li foil with thickness of $550 \mu \mathrm{m}$ ) could not guarantee the successful commercialization of Li metal batteries in the future. This condition is caused by the large excess of Li usage showing no advantages in improving energy density, but exhibiting a capacity degradation during cycling, which might be caused by the low Coulombic efficiency (CE) and uncontrolled Li dendrite growth. Furthermore, the ultrathin Li with thickness of 10-30 $\mu \mathrm{m}$ prepared via abietic resin coating was used as anodes. In comparison with the results in Supplementary Fig. 19f $(\mathrm{Cu}+$ commercial Li/LFP), the full cell exhibited a similar cycling behavior with a retention of $\sim 88 \%$ after 250 cycles (Supplementary Fig. 20a). The capacity calculated based on the (cathode + anode) mass was $85.89 \mathrm{~mA} \mathrm{hg}^{-1}$ for the ultrathin $\mathrm{Li}$ metal 
batteries (Supplementary Fig. 20a), which corresponds to an energy density of $292 \mathrm{Wh} \mathrm{kg}^{-1}$. We achieved a low energy density of $38 \mathrm{Wh} \mathrm{kg}^{-1}$ by increasing the Li:LFP mass ratio to $11.53: 1$ (with commercial $\mathrm{Li}$ metal of $550 \mu \mathrm{m}$ as anode). With the increased CEs and suppressed dendrite growth in Li metal batteries, an increased energy density could be achieved by further reducing the Li/LFP mass ratio. Supplementary Figure 20b displays the cycling behavior of the full cell $\left(\mathrm{Li}-\mathrm{In} / \mathrm{LiFePO}{ }_{4}\right)$. Supplementary Figure 20d compares the voltage profiles of the LFP/ Li cells with different anodes. The specific capacities of the two cells were similar with each other, that is, $135 \mathrm{~mA} \mathrm{~h} \mathrm{~g}^{-1}$ at $0.5 \mathrm{C}$ for the $\mathrm{Li}-\mathrm{Mg}$ anodes, and $140 \mathrm{~mA} \mathrm{~h} \mathrm{~g}^{-1}$ at $0.5 \mathrm{C}$ for the $\mathrm{Li}-\mathrm{In}$ anodes. The similar electrochemical performance might be due to the Li capacity being excessive for cathode capacity (Supplementary Table 5). The ultrathin Li could also be applied in other HED batteries with a $\mathrm{Li}$ metal anode and $\mathrm{Ni}$-rich $\mathrm{Li}\left(\mathrm{Ni}_{x-}\right.$ $\left.\mathrm{Co}_{y} \mathrm{Mn}_{1-x-y}\right) \mathrm{O}_{2}$ cathode, possibly providing new perspectives for the development of high-performance Li metal batteries ${ }^{38,39}$.

In addition to the aforementioned full battery performance, we further investigated the plating behavior and electrochemical properties of ultrathin composite anodes prepared by elemental additives. With planar $\mathrm{Cu}$ as working electrodes, ultrathin $\mathrm{Li}_{x} \mathrm{In}_{y}$ anode (50 wt\% In) deposited onto planar Cu substrate showed an overpotential of $\sim 100 \mathrm{mV}$ at a current density of $1 \mathrm{~mA} \mathrm{~cm}^{-2}$. For commercial $\mathrm{Li}$ anode, the value reached up to $150 \mathrm{mV}$ (Supplementary Fig. 21a, b). In addition to the low overpotential, the morphology of $\mathrm{Li}_{x} \mathrm{In}_{y}$ anode was highly porous after the stripping of Li (Supplementary Fig. 21d), indicating a dealloying reaction during the stripping process ( $\mathrm{Li}$ was extracted from $\left.\mathrm{Li}_{x} \mathrm{In}_{y}\right)$. Moreover, $\mathrm{Li}-\mathrm{Mg}$ anodes prepared via adding $28 \mathrm{wt} \% \mathrm{Mg}$ into molten $\mathrm{Li}$ showed not only compact electrodeposition morphologies (Supplementary Fig. 22a, c) but also low charge transfer resistance and a significant increase in cycling stability (Supplementary Fig. 23a, d), which are properties in contrast with those of the $\mathrm{Li}$ anode. Other elements (e.g., $\mathrm{Hg}, \mathrm{Ba}, \mathrm{Sr}, \mathrm{Y}, \mathrm{Ga}, \mathrm{Pd}$, $\mathrm{Bi}, \mathrm{S}, \mathrm{Se}$, and $\mathrm{Te}$ ) were used as additives to prepare ultrathin anodes, and the resultant anodes exhibited a remarkably compact and uniform electrodeposition during $\mathrm{Li}$ deposition (Supplementary Fig. 24). Thus, suggesting that the ultrathin anodes are promising to be obtained by tuning the wettability of molten $\mathrm{Li}$ via elemental additives.

Similar to molten $\mathrm{Li}$, molten $\mathrm{Na}$ or $\mathrm{K}$ showed poor wettability onto various substrates even though these alkali metals could be used as the promising metal anodes for rechargeable batteries. On the basis of the aforementioned strategies for molten $\mathrm{Li}$, molten $\mathrm{Na}$ was spread on lactic acid-coated $\mathrm{Cu}$ substrates. Subsequently, an ultrathin Na layer $<1 \mu \mathrm{m}$ was successfully produced (Supplementary Fig. 25a). The elemental distribution of $\mathrm{C}, \mathrm{O}$, and $\mathrm{Na}$ at the bottom surface suggests that molten $\mathrm{Na}$ could react with the thermal decomposition products of the organic coating and that the reaction has formed a new interface, thereby improving the wettability of molten $\mathrm{Na}$ (Supplementary Fig. 25b-g). These results suggest the great versatility of our wetting strategy in generating various ultrathin metal anodes and promoting its practical applications in next-generation rechargeable HED batteries.

\section{Discussion}

To better understand the key parameters governing the wettability, we summarized the related compounds and elements that could react with molten $\mathrm{Li}$. As indicated by the aforementioned results, the improved wettability can be mainly attributed to the new chemical bonds formed as a result of the reaction between molten $\mathrm{Li}$ and lithiophilic substances. Given that the $\Delta_{\mathrm{r}} G$ gives the spontaneity of a reaction, from the thermodynamic viewpoint the negative values of $\Delta_{\mathrm{r}} G$ for those reactions were closely related to the improved wettability. $\Delta_{\mathrm{r}} G$ was calculated at a fixed temperature, as shown as follows ${ }^{40}$ :

$$
\Delta_{\mathrm{r}} G=\Delta_{\mathrm{r}} H_{298.15 \mathrm{~K}}-T \Delta_{\mathrm{r}} S_{298.15 \mathrm{~K}},
$$

where $\Delta_{\mathrm{r}} G$ is the Gibbs formation energy for the reaction, $\Delta_{\mathrm{r}} H_{298.15 \mathrm{~K}}$ is the enthalpy change of the reaction at $298.15 \mathrm{~K}$, $\Delta_{\mathrm{r}} S_{298.15 \mathrm{~K}}$ is the entropy change of the reaction at $298.15 \mathrm{~K}$, and $T$ is the reaction temperature. The temperature was set to $523.15 \mathrm{~K}$. $\Delta_{\mathrm{r}} G$ for some feasible reactions at $250^{\circ} \mathrm{C}$ to improve the wettability is shown in Fig. $4 \mathrm{a}$ and Supplementary Table 3. According to Eq. (1), the value of $\Delta_{\mathrm{r}} \mathrm{G}$ could be significantly affected by temperature. For example, lithiophobic $\mathrm{Cu}$ substrates could be lithophilic when the temperature was increased to $\sim 427^{\circ} \mathrm{C}$ according to the $\mathrm{Cu}-\mathrm{Li}$ phase diagram ${ }^{41}$.

Typically, the negative value of $\Delta_{\mathrm{r}} G$ for a specific reaction indicates that the newly formed chemical bond could be formed, which improves the wettability. The $\Delta_{\mathrm{r}} \mathrm{G}$ of the reaction of $\mathrm{Li}$ and $\mathrm{H}_{2} \mathrm{O}$ $\left(-407.7 \mathrm{~kJ} \mathrm{~mol}^{-1}\right)$ was lower than that of $\mathrm{Li}_{2} \mathrm{O}$ and $\mathrm{H}_{2} \mathrm{O}(-74.6 \mathrm{~kJ}$ $\mathrm{mol}^{-1}$; Supplementary Table 3), indicating that the reaction is more favorable for $\mathrm{Li}$ and $\mathrm{H}_{2} \mathrm{O}$ than for $\mathrm{Li}_{2} \mathrm{O}$ and $\mathrm{H}_{2} \mathrm{O}$. Moreover, the reactions of $\mathrm{Li}_{2} \mathrm{O}$ with alloying elements, such as $\mathrm{Mg}, \mathrm{Si}$, and $\mathrm{Sn}$, could not occur, whereas the reaction of $\mathrm{Li}$ with these alloying elements $\left(\Delta_{\mathrm{r}} G<0\right)$ could occur at $250^{\circ} \mathrm{C}$ (Supplementary Table 3 ). As a result, the oxidation of $\mathrm{Li}$ is unfavorable for the wettability of molten Li. Based on this principle, the heating temperature should be controlled, and the oxides of molten Li should be removed as much as possible. The formation of new related bonds, such as $\mathrm{Li}-\mathrm{X}$, which are responsible for improved wettability, is summarized in Fig. 4b. Notably, elements in the periodic table with red color (i.e., $\mathrm{Ti}, \mathrm{Fe}$, and $\mathrm{Cu}$ ) could not react with the molten $\mathrm{Li}$ at the temperature range of $180-300^{\circ} \mathrm{C}$. Thus, the wettability of molten $\mathrm{Li}$ on those substrates is poor (Fig. 4c). On the contrary, lithiophilic coatings with functional groups containing $-\mathrm{N},-\mathrm{P},-\mathrm{F},-\mathrm{Cl},-\mathrm{Br}$, or $-\mathrm{I}$ in blue color could react with molten $\mathrm{Li}$, leading to new bond formation and thus improved wettability. Element additives in green color, such as In and $\mathrm{Mg}$, could also be used to improve the wettability of molten Li. The summarized lithiophilic substances in the periodic table are potentially helpful in understanding the wetting phenomenon of molten alkali metals.

In addition to $\Delta_{\mathrm{r}} G$, the ionic bonding between $\mathrm{Li}$ and abietic acid was considered through the theoretical calculations based on chemisorption. The newly formed ionic bond between $\mathrm{Cu}$ clusters $(\mathrm{Cu}, \mathrm{Cu} 4$, and $\mathrm{Cu} 10)$ and $\mathrm{Li}$ was shown in Fig. 5a-c. The adsorption energies of $\mathrm{Li}$ on $\mathrm{Cu}, \mathrm{Cu} 4$, and $\mathrm{Cu} 10$ clusters were $-150.40,-123.81$, and $-94.28 \mathrm{~kJ} \mathrm{~mol}^{-1}$, respectively. The adsorption energy of $\mathrm{Li}$ on $\mathrm{Cu}$ decreased with the increase of cluster size. Furthermore, the adsorption of $\mathrm{Li}$ atoms on the surface of $\mathrm{Cu}$ would be further reduced in the actual system. The chemisorption energy of $\mathrm{Li}$ on abietic acid was $-426.45 \mathrm{~kJ} \mathrm{~mol}^{-1}$, which is higher than that of $\mathrm{Li}$ on $\mathrm{Cu}$ clusters (i.e., $\mathrm{Cu}, \mathrm{Cu} 4$, $\mathrm{Cu} 10)$. From this point of view, the newly formed ionic bond between $\mathrm{Li}$ and abietic acid (Fig. 5d) was stronger than that of $\mathrm{Li}$ and $\mathrm{Cu}$. Hence, the newly formed chemical bonds might be responsible for improved wettability.

In conclusion, we have developed a feasible chemical strategy for tuning the wettability of molten Li and successfully prepared a series of ultrathin $\mathrm{Li}$ anodes with the assistance of organic coatings with $-\mathrm{COOH},-\mathrm{OH},-\mathrm{SO}_{3} \mathrm{H},-\mathrm{NH}_{2},-\mathrm{NH}-,-\mathrm{Si}-\mathrm{O},-\mathrm{F},-\mathrm{Cl},-\mathrm{Br},-\mathrm{I}$, or elements including $\mathrm{Mg}$, In, $\mathrm{Ca}, \mathrm{Sr}, \mathrm{Ba}, \mathrm{Sc}, \mathrm{Y}, \mathrm{Rh}, \mathrm{Ir}, \mathrm{Pd}, \mathrm{Pt}, \mathrm{Au}$, $\mathrm{Cd}, \mathrm{Hg}, \mathrm{Ga}, \mathrm{Tl}, \mathrm{Ge}, \mathrm{Pb}, \mathrm{As}, \mathrm{Sb}, \mathrm{Bi}, \mathrm{S}, \mathrm{Se}$, and Te. For this newly developed chemical strategy, the mechanisms of improved wettability of molten Li are proposed. Negative values of $\Delta_{\mathrm{r}} G$ for the reactions between molten $\mathrm{Li}$ and lithiophilic substances and the newly formed bonds are regarded as characteristics that govern improved wettability. Furthermore, the chemisorption energy of $\mathrm{Li}$ on abietic acid is higher than that of $\mathrm{Li}$ on $\mathrm{Cu}$ cluster. Hence, the 
a

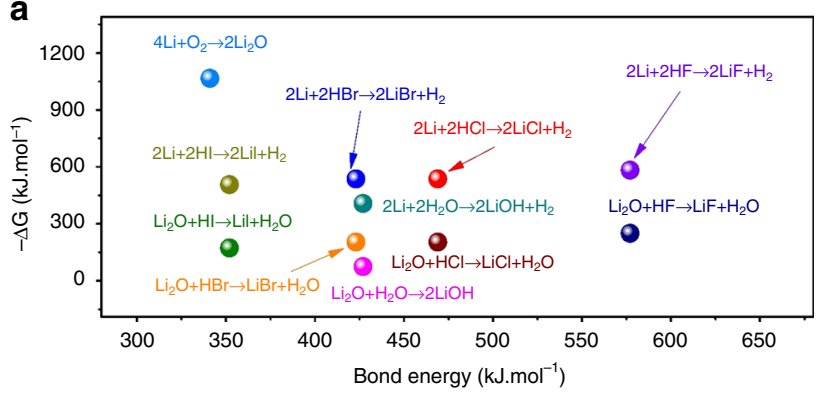

b

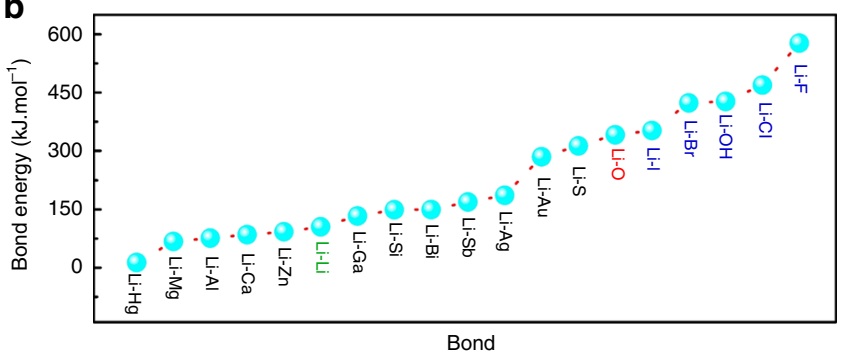

C

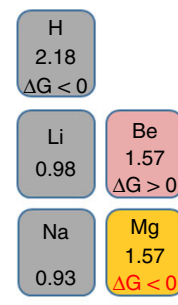

Poor wettability

Good wettability confirmed by previous reports

Good wettability confirmed by this work

$\mathrm{K}$
0.82
1.00
$\Delta \mathrm{G}<0$
$\mathrm{Sc}$
1.36
$\Delta \mathrm{G}<0$
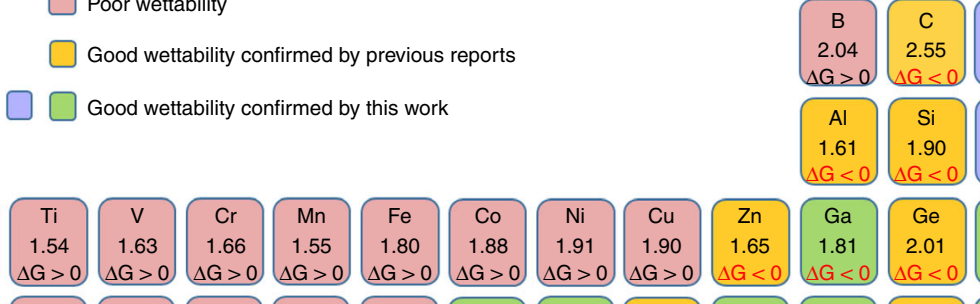

$N$
3.04
$\Delta G<0$
$P$
2.19
$\Delta G<0$

0
3.44
$\Delta G<0$
$S$
2.58
$\Delta G<0$
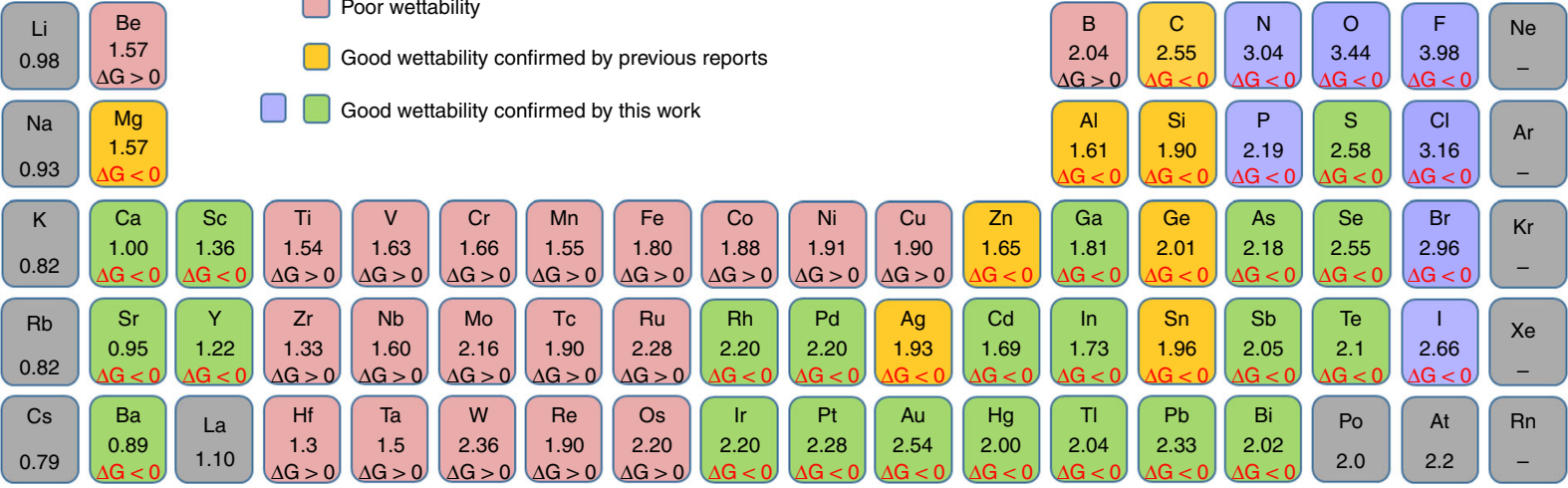

As
2.18
$\Delta G<0$

$\mathrm{Se}$
2.55

$\mathrm{Br}$
2.96
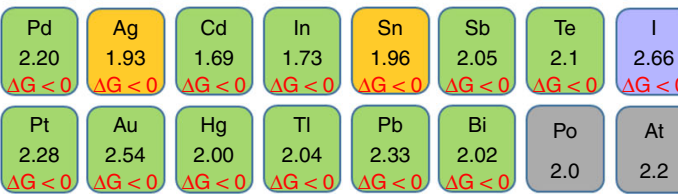

$\begin{array}{ccc}T & P b \\ 2.04 & 2.33 \\ \Delta G<0 & \\ \Delta G<0\end{array}$

$B i$
2.02
$\Delta G<0$
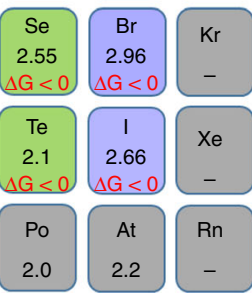

Fig. 4 Common characteristics of wettability onto various lithiophobic substrates. a $\Delta_{r} G$ for some feasible reactions at $250^{\circ} \mathrm{C}$ to improve the wettability. b Bond energies of the newly formed bonds. $\mathbf{c}$ Electronegativities of various elements in the periodic table and $\Delta_{\mathrm{r}} \mathrm{G}$ of elements or compounds reacted with the molten $\mathrm{Li}$. The elements in green and blue colors represent the elements could react with molten $\mathrm{Li}$ at the temperature of $180-300{ }^{\circ} \mathrm{C}$, and form new chemical bonds, which is responsible for the improved wettability
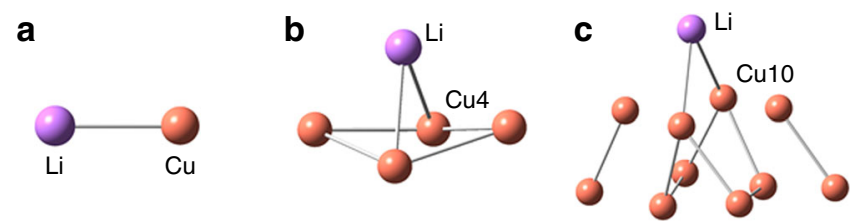

d

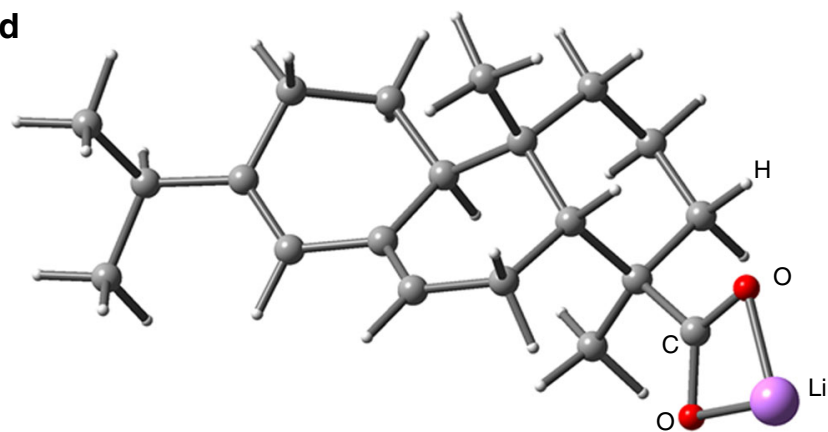

Fig. 5 Theoretical calculation of the newly formed ionic bonds based on chemisorption. a-c The newly formed ionic bond between $\mathrm{Li}$ and $\mathrm{Cu}$ clusters. d The newly formed ionic bond between Li and abietic acid

newly formed strong chemical bonds might be responsible for the improved wettability. As a result, ultrathin $\mathrm{Li}$ with the desired thickness could be easily prepared based on the newly developed, highly efficient, and toolkit-like chemical strategy, which could be successfully applied in HED batteries in the future.

\section{Methods}

Preparation of the abietic resin coating. The doctor-blade coating was adopted to form lithiophilic layers onto various lithiophobic substrates. A series of solutions were prepared. Abietic resin was dissolved in ethanol at a concentration of $5 \mathrm{wt} \%$. $\mathrm{Cu}$ foil and other substrates were coated with the organic coating with thickness of $\sim 200 \mu \mathrm{m}$ (solvent containing). The solvent was fully volatilized before transferring to an argon-filled glove box with an oxygen and moisture $<0.1$ p.p.m. The thickness of the organic coating was $\sim 500 \mathrm{~nm}$ after the volatilization of solvent. The preparation of other organic coatings was similar to the abietic resin.

Preparation of the ultrathin Li layer via organic coatings. The commercialized $\mathrm{Li}$ was heated to $300^{\circ} \mathrm{C}$ for $10 \mathrm{~min}$. The gray oxides formed on molten Li at high temperatures even with the oxygen $<0.1$ p.p.m. The gray oxide layer was removed before the substrates contacted with the molten Li. Ultrathin Li layer could not be formed onto substrates without organic coatings at $180-300^{\circ} \mathrm{C}$. However, the ultrathin Li layer could be observed when substrates were coated with an organic coating such as abietic resin.

Preparation of the ultrathin Li layer via decreasing surface tension of molten Li. Powders of In was added into molten $\mathrm{Li}$ at $300^{\circ} \mathrm{C}$ with a weight ratio of 5,10 , 20 , and $50 \mathrm{wt} \%$, and In was distributed in the composites as homogeneous as possible. The new interphases were formed through a combination reaction. The surface tension of $\mathrm{Li}-\mathrm{In}(5 \mathrm{wt} \% \mathrm{In})$ was not changed visibly. When the content of indium increases to $10 \mathrm{wt} \%$, the surface energy could be tuned obviously. When the surface tension of molten Li was decreased, molten Li could spread onto the lithiophobic substrates such as planar $\mathrm{Cu}$, forming ultrathin Li. Other elemental additives, such as S (10 wt \%), Se (50 wt\%), Te (40 wt \%), Bi (50 wt\%), Pb (50 wt \%), $\mathrm{Ga}(40 \mathrm{wt} \%), \mathrm{Cd}(50 \mathrm{wt} \%), \mathrm{Hg}(50 \mathrm{wt} \%), \mathrm{Pd}(50 \mathrm{wt} \%), \mathrm{Sc}(20 \mathrm{wt} \%), \mathrm{Y}(40 \mathrm{wt} \%), \mathrm{Mg}$ (28 wt\%), Ca (40 wt\%), Sr (50 wt\%), and Ba (50 wt\%), were also investigated as additives to molten $\mathrm{Li}$ with the same procedure to tune the surface energy of molten Li.

\section{Data availability}

All data needed to evaluate the conclusions in the paper are present in the paper and/or the Supplementary Materials. The data that support the results within this paper are available from the corresponding author upon reasonable request. 
Received: 10 March 2019; Accepted: 11 October 2019;

Published online: 30 October 2019

\section{References}

1. Armand, M. \& Tarascon, J. M. Building better batteries. Nature 451, 652-657 (2008).

2. Goodenough, J. B. \& Park, K. S. The Li-ion rechargeable battery: a perspective. J. Am. Chem. Soc. 135, 1167-1176 (2013).

3. Albertus, P., Babinec, S., Litzelman, S. \& Newman, A. Status and challenges in enabling the lithium metal electrode for high-energy and low-cost rechargeable batteries. Nat. Energy 3, 16-21 (2018).

4. Johnson, $\mathrm{L}$. et al. The role of $\mathrm{LiO}_{2}$ solubility in $\mathrm{O}_{2}$ reduction in aprotic solvents and its consequences for $\mathrm{Li}^{-} \mathrm{O}_{2}$ batteries. Nat. Chem. 7, 87-87 (2015).

5. Aetukuri, N. B. et al. Solvating additives drive solution-mediated electrochemistry and enhance toroid growth in non-aqueous $\mathrm{Li}-\mathrm{O}_{2}$ batteries. Nat. Chem. 7, 50-56 (2015).

6. Jung, H. G., Hassoun, J., Park, J. B., Sun, Y. K. \& Scrosati, B. An improved high-performance lithium-air battery. Nat. Chem. 4, 579-585 (2012).

7. Lu, Y., Tu, Z. \& Archer, L. A. Stable lithium electrodeposition in liquid and nanoporous solid electrolytes. Nat. Mater. 13, 961-969 (2014).

8. Zhao, J. et al. Air-stable and freestanding lithium alloy/graphene foil as an alternative to lithium metal anodes. Nat. Nanotechnol. 12, 993-999 (2017).

9. Liu, C., Neale, Z. G. \& Cao, G. Understanding electrochemical potentials of cathode materials in rechargeable batteries. Mater. Today 19, 109-123 (2016).

10. Tikekar, M. D., Choudhury, S., Tu, Z. \& Archer, L. A. Design principles for electrolytes and interfaces for stable lithium-metal batteries. Nat. Energy 1, 16114 (2016)

11. Li, W. et al. The synergetic effect of lithium polysulfide and lithium nitrate to prevent lithium dendrite growth. Nat. Commun. 6, 7436 (2015).

12. Liang, $\mathrm{X}$. et al. A facile surface chemistry route to a stabilized lithium metal anode. Nat. Energy 2, 17119 (2017).

13. Zheng, J. et al. Electrolyte additive enabled fast charging and stable cycling lithium metal batteries. Nat. Energy 2, 17012 (2017).

14. Lin, D., Liu, Y. \& Cui, Y. Reviving the lithium metal anode for high-energy batteries. Nat. Nanotechnol. 12, 194-206 (2017).

15. Zhang, R. et al. Lithiophilic sites in doped graphene guide uniform lithium nucleation for dendrite-free lithium metal anodes. Angew. Chem. Int. Ed. 56, 7764-7768 (2017).

16. Yang, C. et al. Ultrafine silver nanoparticles for seeded lithium deposition toward stable lithium metal anode. Adv. Mater. 29, 1702714 (2017).

17. Li, N. W., Yin, Y. X., Yang, C. P. \& Guo, Y. G. An artificial solid electrolyte interphase layer for stable lithium metal anodes. Adv. Mater. 28, 1853-1858 (2016).

18. Liu, L. et al. Uniform lithium nucleation/growth induced by lightweight nitrogen-doped graphitic carbon foams for high-performance lithium metal anodes. Adv. Mater. 30, 1706216 (2018).

19. Wang, S. H. et al. Stable Li metal anodes via regulating lithium plating/ stripping in vertically aligned microchannels. Adv. Mater. 29, 1702714 (2017).

20. Zheng, G. et al. Interconnected hollow carbon nanospheres for stable lithium metal anodes. Nat. Nanotechnol. 9, 618-623 (2014).

21. Zuo, T. T. et al. Trapping lithium into hollow silica microspheres with a carbon nanotube core for dendrite-free lithium metal anodes. Nano Lett. 18, 297-301 (2018).

22. Liu, W. et al. Core-shell nanoparticle coating as an interfacial layer for dendrite-free lithium metal anodes. ACS Cent. Sci. 3, 135-140 (2017).

23. Lin, D. et al. Layered reduced graphene oxide with nanoscale interlayer gaps as a stable host for lithium metal anodes. Nat. Nanotechnol. 11, 626-632 (2016).

24. Wang, C. et al. Universal soldering of lithium and sodium alloys on various substrates for batteries. Adv. Energy Mater. 8, 1701963 (2018).

25. Zhang, R. et al. Coralloid carbon fiber-based composite lithium anode for robust lithium metal batteries. Joule 2, 764-777 (2018).

26. Liang, Z. et al. Composite lithium metal anode by melt infusion of lithium into a 3D conducting scaffold with lithiophilic coating. Proc. Natl Acad. Sci. USA 113, 2862-2867 (2016)

27. Liu, Y. et al. Lithium-coated polymeric matrix as a minimum volume-change and dendrite-free lithium metal anode. Nat. Commun. 7, 10992 (2016).

28. Zhang, Y. et al. High-capacity, low-tortuosity, and channel-guided lithium metal anode. Proc. Natl Acad. Sci. USA 114, 3584-3589 (2017).

29. Fu, K. K. et al. Toward garnet electrolyte-based Li metal batteries: an ultrathin, highly effective, artificial solid-state electrolyte/metallic Li interface. Sci. Adv. 3, 1601659 (2017).

30. Luo, W. et al. Transition from superlithiophobicity to superlithiophilicity of garnet solid-state electrolyte. J. Am. Chem. Soc. 138, 12258-12262 (2016).
31. Wang, C. et al. Conformal, nanoscale $\mathrm{ZnO}$ surface modification of garnet-based solid-state electrolyte for lithium metal anodes. Nano Lett. 17, 565-571 (2017)

32. Han, X. et al. Negating interfacial impedance in garnet-based solid-state Li metal batteries. Nat. Mater. 16, 572-579 (2017).

33. Fu, K. K. et al. Transient behavior of the metal interface in lithium metalgarnet batteries. Angew. Chem. Int. Ed. 56, 14942-14947 (2017).

34. Kang, J., Kim, H. V., Chae, S. A. \& Kim, K. H. A new strategy for maximizing the storage capacity of lithium in carbon materials. Small 14, 1704394 (2018).

35. Wertheim, G. K., Van Attekum, P. M., Th., M. \& Basu, S. Electronic structure of lithium graphite. Solid State Commun. 33, 1127-1130 (1980).

36. Sangster, J. C-Li (carbon-lithium) system. J. Phase Equilib. Diff. 28, 561-570 (2007).

37. Duan, J. et al. Lithium-graphite paste: an interface compatible anode for solidstate batteries. Adv. Mater. 31, 1807243 (2019).

38. Hwang, J. Y., Park, S. J., Yoon, C. S. \& Sun, Y. K. Customizing a Li-metal battery that survives practical operating conditions for electric vehicle applications. Energy Environ. Sci. 12, 2174-2184 (2019).

39. Lee, S. H., Hwang, J. Y., Park, S. J., Park, G. T. \& Sun, Y. K. Adiponitrile $\left(\mathrm{C}_{6} \mathrm{H}_{8} \mathrm{~N}_{2}\right)$ : a new Bi-functional additive for high-performance Li-metal batteries. Adv. Funct. Mater. 29, 1902496 (2019).

40. Derek, W. Smith Electronegativity in two dimensions. J. Chem. Edu. 67, 911-914 (1990).

41. Gąsior, W., Onderka, B., Moser, Z., Dẹbski, A. \& Gancarz, T. Thermodynamic evaluation of $\mathrm{Cu}-\mathrm{Li}$ phase diagram from EMF measurements and DTA study. Calphad 33, 215-220 (2009).

\section{Acknowledgements}

This work was supported by the Basic Science Center Project of National Natural Science Foundation under Grant No. 51788104, the National Key R\&D Program of China (Grant No. 2016YFA0202500), the "Transformational Technologies for Clean Energy and Demonstration" Strategic Priority Research Program of the Chinese Academy of Sciences (Grant no. XDA21070300), the National Natural Science Foundation of China (Grant Nos. 21773264 and 51772301), the National Postdoctoral Program for Innovative Talents (Grant No. BX201600171), and the China Postdoctoral Science Foundation (Grant No. 2017M611003).

\section{Author contributions}

Y.-G.G. proposed and supervised the project. S.-H.W., Y.-X.Y., and Y.-G.G. conceived and designed the experiments. X.L. conducted theoretical calculations to explain the improved wettability. S.-H.W. carried out the experiments with the help from J.Y., W.D., T.-T.Z., J.-Y.L, X.-D.Z., L.L., and J.-L.S. All authors participated in the analysis of the experimental results. S.-H.W., Y.-X.Y., and Y.-G.G. participated in preparing the paper.

\section{Competing interests}

The authors declare no competing interests.

\section{Additional information}

Supplementary information is available for this paper at https://doi.org/10.1038/s41467019-12938-4.

Correspondence and requests for materials should be addressed to Y.-G.G.

Reprints and permission information is available at http://www.nature.com/reprints

Publisher's note Springer Nature remains neutral with regard to jurisdictional claims in published maps and institutional affiliations.

\section{Attribution 4.0 International License, which permits use, sharing,} adaptation, distribution and reproduction in any medium or format, as long as you give appropriate credit to the original author(s) and the source, provide a link to the Creative Commons license, and indicate if changes were made. The images or other third party material in this article are included in the article's Creative Commons license, unless indicated otherwise in a credit line to the material. If material is not included in the article's Creative Commons license and your intended use is not permitted by statutory regulation or exceeds the permitted use, you will need to obtain permission directly from the copyright holder. To view a copy of this license, visit http://creativecommons.org/ licenses/by/4.0/.

(C) The Author(s) 2019 